\title{
LOS MODELOS DE EXPLOTACIÓN DE LOS RECURSOS LÍTICOS DURANTE EL PLEISTOCENO DE LA REGIÓN DE MADRID
}

\section{MODELS OF LITHIC RESOURCES EXPLOITATION DURING THE PLEISTOCENE IN THE MADRID REGION}

\author{
por \\ CONDE RUIZ CARMEN* \\ BAENA PREYSLER JAVIER* \\ CARRIÓN SANTAFÉ ELENA*
}

\begin{abstract}
RESUMEN En el presente trabajo presentamos algunas reflexiones sobre las estrategias de captación y transformación lítica en el Paleolítico del Valle del Manzanares. Comenzamos con un repaso de algunas de los modelos implicados y su desarrollo a lo largo del tiempo, para adentrarnos más tarde en la problemática específica que el estudio de las colecciones antiguas presenta. Así mismo, ofrecemos algunos datos preliminares sobre los materiales procedentes de la Colección Bento, y su posible correspondencia con yacimientos del todavía mal conocido Paleolítico Superior madrileño, en relación con las áreas de captación.
\end{abstract}

\begin{abstract}
This paper outlines some reflexions about raw materials lithic transformation in Palaeolithic sites of the Manzanares Valley. Firstly we present a review of the flint supply and catchment models and its development along the time. We also introduce the specific problems of studies of ancient collections. Otherwise, we try to determine some preliminary data about the materials from Bento Collection and their relationship with Upper Palaeolithic sites, as well as their significance as raw material adquisition areas.
\end{abstract}

Palabras claves Paleolítico, sílex, taller, Manzanares

Key words Palaeolithic, fluit, workshop, Manzanares

* Departamento de Prehistoria y Arqueología de la Universidad Autónoma de Madrid. 


\section{ESTADO ACTUAL DE LAS INVESTIGACIONES SOBRE EL PALEOLÍTICO EN LA ZONA}

Dada la reciente aparición de síntesis actualizadas sobre la evolución historiográfica del Paleolítico madrileño en las últimas décadas (Rus 1987; Baena et al.2000), obviamos en el presente trabajo un estudio historiográfico más detallado. Aludiremos por ello de forma sucinta al desarrollo de la investigación paleolítica en el ámbito madrileño.

Sin duda, los primeros hallazgos prehistóricos de la provincia de Madrid, fueron el motor de la investigación prehistórica a nivel peninsular. De entre ellos, el yacimiento del Cerro de San Isidro fue el abanderado más destacado, llegando incluso a ser comparado con "los grandes sitios franceses". Su descubrimiento dio lugar a numerosas publicaciones en diversos medios, tanto dentro como fuera de nuestras fronteras, creando así, un fructífero tránsito de ideas e investigadores que condicionaron en gran medida nuestra disciplina científica a lo largo del primer tercio del siglo XX. El río Manzanares pasó así a convertirse en un foco de interés dentro de los estudios de la Prehistoria peninsular.

Desde estos primeros momentos, la investigación del Paleolítico en Madrid se observa una alternancia de etapas con gran profusión investigadora arropados por proyectos e iniciativas de investigación de gran envergadura, junto a largos periodos de abandono o letargo. La primera fase fructífera es la que se comprende entre los años 1917 y 1936, en especial gracias a la labor de investigadores como H. Obermaier, P. Wernet y J. Pérez de Barradas, quienes en la primera mitad de este siglo, excavaron yacimientos paleolíticos tan emblemáticos como Las Carolinas (Obermaier 1917), Las Delicias (Obermaier y Wernet 1918) o las Canteras de Vallecas (Obermaier et al. 1921), entre otros. Estos investigadores fueron los responsables de dar a conocer los principales hallazgos prehistóricos y a su vez los creadores de las primeras secuencias culturales en nuestro entorno (Priego 1999). Gracias a estos autores, hoy tenemos numerosos datos sobre el Paleolítico del Valle del Manzanares; que de otra forma no se habrían conocido (Rus 1987). Después de este momento de esplendor, con la llegada de la Guerra Civil, la investigaciones sobre Paleolítico se interrumpen bruscamente. Únicamente los trabajos y recompras de los años 40 de la mano de Martínez Santa-Olalla, pudieron enmascarar una verdadera ausencia de investigación en este campo.

En las décadas de los 70 y los 80 encontramos una nueva reactivación sobre los trabajos en esta región, desde nuevas propuestas metodológicas que tratan de aunar campos muy diversos (Arqueozoología, Palinología, Estadística, etc.) y que tienen como corolario el trabajo en el yacimiento de Áridos (Santonja et al. 1980). Entre los investigadores más destacados durante estos momentos no podemos dejar de citar a M. Santonja, Mª Q Querol, I. Rus, V. Cabrera, G. Vega, J. Enamorado, C. Férnandez Rojas, M. Gamazo, A. Cobo, A. Martínez de Merlo, J. Sánchez, C. Rodríguez, sin olvidar la colaboración desde otros campos de A. Pérez González, M. Hoyos, E. Soto o C. Sesé entre otros muchos.

Tras esta fase hemos dado paso a una etapa de vacío en la investigación (Rubio et al. 1999) que coincide con la promulgación de la nueva Ley de Patrimonio de 1985 y con la trasferencia de competencias entre las antiguas Diputaciones a las nuevas Comunidades Autónomas. Comienza a partir de estos momentos a surgir la denominada Arqueología de Gestión, y con ella muchos de los males que en la actualidad aquejan a la investigación de la Prehistoria madrileña (Baena et al. 2000).

La falta de Proyectos globales de investigación para la Prehistoria madrileña ha conducido a un claro distanciamiento entre los centros de investigación (especialmente las Universidades) y los propios organismos encargados de la gestión patrimonial. La implantación de esta esperada “Arqueología de Gestión” ha producido estos últimos años serios problemas que culminan con la falta de control y difusión de los avances en este campo, y fruto de todo ello, con la ausencia de estudios sobre los yacimientos paleolíticos. A la larga, esta situación obligará a revisiones de colecciones en los Museos, con los problemas que debido al paso del tiempo, ello comporta. 
Sin embargo, durante estos últimos 10 años se han producido aportaciones aisladas como los trabajos de Pedazo del Muerto (López Covacho et al. 1996), La Dehesa (Rodríguez Cifuentes et al. 1996) o Salmedina (Baena et al. 1998). También hay que destacar los trabajos en yacimientos previamente conocidos como los de la publicación de Orcasitas (Quero 1994) o Transfesa-El Espinillo (Silva et al. 1998).

Recientemente parece haberse superado esta situación gracias a una mayor sensibilidad por parte de algunas instituciones e investigadores particulares, así mismo con la creación del Museo Regional de la C.A.M. Nuevos proyectos de investigación han sido concedidos por la Dirección General de Patrimonio Cultural de la C.A.M., proyectos que pretenden profundizar el conocimiento de la secuencia del Jarama con especial incidencia en el Pleistoceno superior -Arganda IV- (Rubio et. al 1999; Panera et al. 2000; Panera et al. e.p.).

\section{CONTINUIDAD O RUPTURA EN LOS MODELOS DE CAPTACIÓN}

El concepto de cadena operativa ha ido introduciéndose en los últimos años de forma generalizada en los estudios líticos, convirtiéndose en parte esencial de la comprensión de las actividades humanas en el marco espacial de su comportamiento. Desde esta percepción, el estudio de los conjuntos industriales pasa inicialmente por analizar no sólo la industria en sí misma, sino también los modos en que se produce la captación de la materia prima y sus primeras fases de transformación.

Para el Paleolítico Antiguo viene asumiéndose la existencia de estrategias de aprovisionamiento lítico escasamente desarrolladas, que definen áreas de intervención limitadas al territorio inmediato (Straus 1992). Mientras en el Paleolítico Inferior se detecta una utilización casi exclusiva de rocas locales [con una coincidencia general de las fases adquisición, producción y consumo en espacios específicos, estrategia que ha sido definida en ocasiones como inmediatez (Montes 1998)]; ya en el Musteriense asistimos a la presencia puntual de materiales considerados exóticos o foráneos, en función tanto de una supuesta ampliación del territorio de aprovisionamiento como de una consideración más selectiva del valor y calidad de las materias trabajadas. Ello supone que las variedades líticas que implican un mayor coste energético de obtención y transporte son objeto de un tratamiento distintivo, muchas veces asociadas a cadenas técnicas más complejas -Levallois-(Stahl y Detrey 1999; Geneste 1988). Pero en general se observa la coincidencia de las materias primas de los yacimientos con la oferta presente en el entorno inmediato, con procedencias que raras veces superan los $5 \mathrm{~km}$; dentro de este radio aproximado, se produce la obtención del $80 \%$ del material utilizable. Este porcentaje aumenta en los conjuntos con industrias Quina, donde la captación se produce con una gran proximidad al yacimiento (Turq 1992) en relación con la economía de medios que suele asociarse a esta facies; sin embargo la aparición en estos yacimientos de materias primas de alta calidad implicaría su mayor condicionamiento a la hora de elegir la ubicación de los asentamientos.

Durante el Musteriense aparece un porcentaje inferior al 20\% de materias primas captadas en espacios comprendidos entre los 5 y los $20 \mathrm{~km}$, siendo ocasional la presencia de materiales de territorios más lejanos. En momentos finales del Paleolítico Medio han podido constatarse esporádicos transportes de hasta 200 y $300 \mathrm{~km}$, en lo que puede ser considerada por algunos, como una progresiva complejidad del territorio de aprovisionamiento (Flébot-Augustins 1999), aunque este tipo de estrategias han sido constatadas (transportes de hasta $100 \mathrm{~km}$ ) para momentos rissienses en el Oeste de Alemania-Remagen-(Floss 1991). Igualmente, en algún caso próximoriental se ha documentado la presencia de incipiente minería (Vermeersch 1988; Vermeersch et al. 1991).

Durante este periodo el grado de transformación de la materia prima sería directamente proporcional al coste energético de su obtención. Así mismo, en teoría, cabe esperar una organización de las actividades en el espacio, de manera que los lugares centrales de ocupación mostrarán distintos tramos de la cadena 
operativa dependiendo de la organización territorial de la producción. El aprovisionamiento de materias primas de calidad (generalmente sílex) puede asociarse a recogidas de carácter oportunista (entendiendolo fuera de su sentido peyorativo, y en todo momento compatible con modelos de adquisición más organizados) en el entorno inmediato (Geneste 1988). Así, durante el Paleolítico Antiguo las estrategias de aprovisionamiento parecen fuertemente dependientes de las pautas de movilidad y la duración de la ocupación, por lo que son fuertemente cambiantes (Kuhn 1995); intervendría una noción de predictibilidad en el transporte selectivo de los nódulos, los núcleos desbastados o las matrices, en función de las posibilidades territoriales de aprovisionamiento. Ello podría afectar a su vez a las características tecnotipológicas de la industria, de manera que pudieran en estos casos darse mayores grados de reavivado o reaprovechamiento de las matrices producidas (Kuhn 1995; Dibble 1988; Loodts 1998).

Este esquema general puede matizarse sin embargo con la aplicación de nociones de funcionalidad en los yacimientos. Han sido constatadas en el Paleolítico Antiguo estrategias que implican la visita reiterada a zonas que son objeto de captación recurrente y donde se produce una talla inicial, somera y exploratoria de recursos conocidos. Estos amplios palimpsestos presentan el problema de la discriminación de la contemporaneidad, tanto a nivel geológico como ocupacional (Conard 1998) que dificulta en gran medida el estudio de las cadenas operativas asociadas. En teoría, esta abundancia de materia prima de calidad habría condicionado, según el que ha sido denominado efecto Commont (Rolland 1998), la sofisticación de las cadenas técnicas implicadas. Cabría esperar en ellos la presencia de esquemas productivos Levallois con traslado de matrices a los lugares centrales, siempre dependiendo de los modelos explicativos empleados que justificasen una mayor o menor dispersión espacial de las evidencias líticas (Stahl y Detrey 1999).

Por otra parte, ya en el Paleolítico Inferior se constata la presencia de cierta selección por calidades de la materia prima en función de los objetivos deseados (Bosinski 1995). El Musteriense cantábrico ofrece un interesante ejemplo con el uso específico de la ofita para la fabricación de macroutillaje, aprovechamiento que implica desplazamientos a afloramientos primarios conocidos. De igual manera en el contexto madrileño del Manzanares, el empleo diferencial de la cuarcita procedente de la cuenca del Jarama, para la elaboración de macroutillaje o como percutores, muestra cómo se producen desviaciones al modelo de captación dominante. La exigencia podría entonces ser considerada como un fenómeno atemporal ligado íntimamente a necesidades técnicas que se encuentran en progresión, haciéndose imperiosas con el desarrollo de la leptolitización.

Desde el punto de vista de la materia prima importada, puede hacerse una discriminación entre distintas categorías de yacimientos (Tavoso 1984):

1. Yacimientos que coinciden con afloramientos de materia prima. Talleres. Las series, atípicas y monótonas, suelen ser riquísimas. En ellas aparecen productos de talla escasamente transformados, exportándose gran parte del material. El Índice Levallois tipológico suele ser excepcionalmente alto, debido a la ausencia de retoque en las matrices. El Índice Levallois técnico, por el contrario, es limitado. Como es lógico la presencia de materia prima sin trabajar, o con un grado de transformación bajo está muy bien representada (en determinados espacios orientados a la captación y transformación masiva podría asumirse la presencia de actividades de aprendizaje colectivo, lo que habría producido variaciones en los porcentajes de determinadas fases de trabajo).

2. Yacimientos con materia prima introducida desde espacios cercanos, generalmente en forma de riñones, cantos, bloques, etc. Suelen coincidir con lugares de hábitats en cueva, y en ellos se encuentra comprendida toda la cadena de talla desde el descortezado hasta el retoque. Consideramos que por una noción mínima de economía, las primeras fases de tanteo o exploración de bloques se produciría en el lugar inmediato a la captación, trasladándose solamente aquellas matrices ya desbastadas o de mejores calidades. Esta circunstancia sería sobre todo evidente en los contextos de mayor exigencia técnica en la producción, que requerirían de materias primas de calidades y estados más depurados. 
3. Yacimientos en los que está presente materia prima más alejada, y en los que han sido introducidos lascas y núcleos ya preparados para la explotación. Es limitada la presencia de lascas corticales, pero el índice Levallois es, por el contrario, muy elevado. Evidentemente la noción de sofisticación técnica de las industrias con predeterminación Levallois deriva de una consideración inicial, casi estilística, en su caracterización. Otros métodos de talla pueden adaptarse con igual precisión a la funcionalidad prevista para los productos, con lo que el concepto de calidad en los esquemas técnicos se encuentra necesitado de una revisión conceptual.

4. Yacimientos que se corresponden con una breve ocupación humana, generalmente en espacios en altura. Es común la ausencia de núcleos y desechos de talla, ya que no se produce en los mismos una transformación del material. Los útiles están bien representados, pudiendo interpretarse como centros de consumo con materiales que han sido elaborados en el taller o talleres correspondientes; las materias primas que aparecen en estos lugares suelen ser el resultado de procedencias muy diversas (Díez Martín 2000).

Durante el Paleolítico Superior los territorios de intervención no son necesariamente más grandes que aquéllos de momentos anteriores, pero se produce un cambio importante en el esfuerzo aplicado a la obtención de materia prima (Geneste 1988). La principal consecuencia es el aumento del porcentaje de materiales procedentes de zonas alejadas, en función de una exigencia técnica mayor, y, sobre todo, la presencia de mecanismos de intercambio y transporte más sofisticados en relación con una mayor anticipación económica. Si durante el Musteriense se nos ha ofrecido la imagen de un aprovechamiento masivo de depósitos secundarios, en momentos más avanzados se observa una fuerte selección de rocas silíceas y de calidades específicas en los lugares directos de afloramiento, aunque, como veremos en el caso que nos ocupa, seguimos detectando la explotación de lugares que nosotros consideramos como depósitos agregados, frecuentemente localizados, en nuestra área de estudio, como depósitos secundarios más o menos alejados de los afloramientos iniciales (Baena et al. 1998), y conformando extensiones dotadas de una explotación asombrosamente recurrente a lo largo del tiempo.

La dependencia de la calidad aumentaría durante el Paleolítico Superior y momentos posteriores, con una etapa de transición, el Chatelperroniense, donde los esquemas son todavía semejantes al Musteriense (Turq 1996). El Auriñaciense marca el comienzo de la presencia de materias primas alejadas, con ejemplos como el transporte de sílex de Bergeracois hasta Isturitz y Antoliñako Koba (Tarriño et al. 1988) ${ }^{1}$. Sin embargo, la distribución espacial de los movimientos en estos momentos avanzados parece semejante a los de etapas previas, cambiando básicamente el porcentaje de elementos fabricados en materiales foráneos (es decir, la intensidad de los transportes). Por otra parte, durante estos momentos siguen observándose lugares de captación (talleres) donde tiene objeto una primera transformación de la materia prima (Klaric 1998; Ortega 1998) sobre depósitos primarios y secundarios. Se manifiesta una progresiva aparición en los lugares centrales de materias primas de calidad, a veces de procedencias alejadas (Maroto et al. 1996; Terradas 1998) pero siempre con un potencial tecnológico elevado dadas las crecientes necesidades. La diferenciación macroscópica de las distintas variedades de sílex y su asociación con aptitudes específicas parece haber estado presente a partir del Magdaleniense, manifestándose en un uso diferencial de la calidades en función de parámetros como el utillaje proyectado y su necesidad de resistencia (Mangado 1998).

La lógica hace suponer que allí donde los materiales ofertados directamente por el medio fueran de calidad aceptable no serían necesarios los desplazamientos que se constatan en otros ámbitos. Por ello en los contextos de ocupación prolongada donde abunda el sílex, durante el Paleolítico Superior se asiste a una continuidad de su transformación en los puntos de abastecimiento o un progresivo aumento de su presencia en los lugares

1. A. Turq no descarta para estos desplazamientos de material los mecanismos de trueque a pequeña escala (troc de proche en proche) (TURQ 1996). 
de hábitat (Cantábrico Oriental; Arrizabalaga 1998). La escasez de evidencias sobre esta última categoría de yacimientos en el área que nos ocupa limita, como veremos, las posibilidades interpretativas; quizás hubiera una coincidencia entre los lugares de aprovisionamiento y los de hábitat, tal como ha sido constatado en algún yacimiento del tramo final del Tajo (Maíllo Fernández 1999).

Por otra parte, la barrera Paleolítico Antiguo/Paleolítico Superior no parece tan nítida como se ha pretendido, al menos en sus momentos iniciales. Esta circunstancia, contrastable en otros contextos, podría ser aún más acentuada en un ambiente tan peculiar como el madrileño, en el que los recursos de todo tipo podrían fomentar la continuidad de los modelos de explotación del entorno.

Durante el Epipaleolítico, quizás en relación con una dependencia técnica menor, los recursos locales vuelven a ser aprovechados y se aprecia un descenso de la rentabilidad en los mecanismos de explotación (Terradas 1995); sin embargo se mantiene aún la utilización específica de variedades de calidad para tipos concretos. La movilidad desciende, así como la exigencia de calidad; se ponen en juego ahora estrategias de captación que implican un coste energético limitado. Tal reducción generalizada de los territorios de aprovisionamiento podría ponerse en relación con el posible aumento demográfico asociado (Tarriño y Aguirre 1997).

\section{ESTRATEGIAS DE CAPTACIÓN EN EL CENTRO PENINSULAR}

A nivel peninsular, venimos contando en los últimos años con una creciente representación de sitios arqueológicos cuya funcionalidad parece asociada, de una manera más o menos directa, y siempre dentro de los límites interpretativos que imponen estos yacimientos, a la captación y transformación de recursos líticos. Por lo general estos yacimientos se caracterizan por la abundancia de restos tallados, distribuidos en superficies más o menos extensas (Raposo y Santona 1995; Díez Martín 2000), y normalmente en clara asociación a depósitos naturales de materias primas sin trabajar. Estos lugares, suelen ser reiteradamente visitados con una misma finalidad lo que acaba creando verdaderos palimpsestos. A falta de una mejor representación de los mismos, por el momento resulta complejo el análisis de su distribución, pero contamos con puntos importantes en zonas como la cuenca del Manzanares en Madrid (Gamazo et al. 1983; Baena Preysler 1993; Baena Preysler et al. 1997), el centro de los yacimientos de Ciudad Real, tales como Porzuna o Casa de la Mina (Vallespí et al. 1979 y 1985; Martín Blanco et al. 1994), Cerro del Molino de San Cristóbal, en Toledo (López Recio et al. e.p.). Otros ejemplos serían el yacimiento de la Coca, Alicante (Fernández Peris 1998) o El Habario (Cantabria; Carrión y Baena 1999), entre otros.

\section{EI Paleolítico Inferior y Medio}

Centrándonos en nuestra zona de estudio, las industrias del Paleolítico Inferior y Medio aparecen concentradas en las cuencas del Manzanares, Jarama, Henares y Tajo, de forma también significativa en sus cauces secundarios (Baena 1995), con algunos ejemplos significativos pero escasos por el momento en la zona del Sistema Central al norte de la Comunidad -zona de Redueña, Torrelaguna, etc.- (Cabra et al. 1983; Rus 1987). El área meridional, coincidente con la cuenca sedimentaria Terciaria, actual depresión del Tajo, se ha caracterizado a lo largo de todo el Pleistoceno por ser una zona especialmente rica en recursos tanto bióticos como litológicos.

Para las fases más antiguas, la interpretación sobre los modelos de explotación de los recursos líticos, ha tendido a basarse fundamentalmente en los yacimientos interpretados desde propuestas africanas (Isaac 1971) como áreas de aprovechamiento de recursos faunísticos, y cambio para nuestro ámbito, siempre cabe 
preguntarse la verdadera relación estratigráfica y por tanto de coetaneidad, existente entre los restos industriales y faunísticos (Santonja et al.1997). En nuestra opinión basar los modelos de aprovechamiento y captación de recursos líticos a partir de este tipo de yacimientos, es un error que parte del empleo de una muestra sesgada (que además responde a actividades oportunistas) y que, como es lógico, conducen a la explotación de recursos de forma inmediata. No entenderlo así implicaría limitar el marco de las actividades humanas al entorno fluvial, dato más que discutido, como se constata en otros ejemplos peninsulares (Carbonell et al. 1995; Díez Martín 2000) y reducir la capacidad de previsión de estas comunidades primitivas a niveles inferiores a los de una ardilla. Aunque los ejemplos clásicos como los de San Isidro (Santonja 1977), Áridos II (Santonja et. al. 1980), Arriaga (Rus 1984), la Aldehuela (Cobo et al. 1994), Transfesa (Menéndez et al. 1958) y Orcasitas (Quero 1994) responden a un aprovechamiento intensivo de fauna mediante el empleo prioritario de materias primas de origen local, en la mayor parte de los casos se documenta igualmente la presencia, insistimos, excepcional en cuanto a su representatividad, de materias primas aloctónas o bien de muy escasa representación en el medio.

Los depósitos sobre los que se desarrolla en estos casos la captación son de tipo secundario (agregados), como se constata por la presencia de alteraciones tales como roturas de pátina, rodamientos en las superficies corticales, etc. (Rus y Enamorado 1991). Pero quizá lo más interesante de este tipo de hallazgos es que al menos parte del utillaje fuese introducido en la zona de actuación, previamente configurado (Domínguez Rodrigo 1994; Martos 1998). Este punto define, de manera implícita, la existencia de otro tipo de yacimientos fuera de las áreas de despedazado destinados a la captación de bases naturales o nódulos y a la configuración inicial del utillaje retocado.

Una prueba de la existencia de esta actividad complementaría, sin duda sujeta a matices en cuanto a su verdadero sentido funcional (mayor o menor carácter de captación, presencia de restos que atestigüen la transformación inicial de las base o de los soportes, etc.), la tenemos dentro de la Comunidad de Madrid en yacimientos como los de Perales del Río (Gamazo et al. 1983) o Soto e Hijos (Baena 1995), ambos en terraza. Los restos de estos yacimientos se caracterizan por la clara asociación de bases naturales y elementos de talla mayoritariamente en sus fases iniciales. Suponemos para estos espacios una actividad de talla intensiva desarrollada en función de la presencia de depósitos agregados de materia prima cerca de los cauces fluviales, que habrían funcionado como focos de aprovisionamiento y transformación en principio sin otras actividades asociadas. A nuestro juicio, la consideración de afloramiento primarios/secundarios es menos trascendente a la hora de analizar las estrategias de captación, que la consideración del carácter agregado/no agregado de los mismos; un afloramiento secundario puede funcionar como un afloramiento primario cuando la densidad de materia prima que se ofrece es elevada

Además de los yacimientos anteriores, situados en posición estratigráfica, aparece otra serie de yacimientos superficiales que ocupan grandes extensiones escasamente acotadas (Rus y Velasco 1993; Baena Preysler $e t$ al. 1998; Baena Preysler et al. 2000); en ellos aparece igualmente una gran cantidad de restos líticos trabajados junto con abundantes bloques de materia prima en bruto (sílex) procedentes del desmantelamiento de los niveles silíceos de los relieves estructurales. Es el caso de los yacimientos del área de Vallecas (Obermaier et al. 1921), La Gavia I (Rus et al. 1993), Salmedina (Baena et al. 1997) o Pedazo del Muerto (López Covacho et al. 1996).

En esto casos, suelen presentarse un variado conjunto de alteraciones fluviales (rodamiento), provocado por el desmantelamiento de zonas de captación, aguas arriba de antiguos cauces. Probablemente se trate de extensas áreas de talla acumuladas a lo largo de amplios periodos de tiempo, tal y como se describen para la zona de la Mancha (Raposo y Santonja 1995), yacimientos que poseen una gran heterogeneidad tanto técnica como en sus alteraciones. La relativa diversidad de los productos técnicos recogidos en estas superficies parece indicarnos que también en este caso, nos enfrentamos a yacimientos cuya utilización ha sido intensiva a lo largo del tiempo. 
Con independencia de los periodos a que pudieran adscribirse los materiales localizados, nos encontraríamos por tanto con dos modelos diferentes en la captación: uno de captación directa o cercana a los afloramientos (Cerro Almodóvar y sus alrededores, Cerro del Telégrafo, Cerro de los Ángeles y sus laderas, etc.) y otro de captación sobre depósitos intensamente agregados pero en contextos más o menos cercanos al cauce fluvial (Perales del Río, Soto e Hijos, Las Fronteras, etc.). Junto a estos, aparece un posible tercer modelo constituido por la disgregación de tales depósitos, como en el Camino del Salmedina y Canteras de Vallecas, etc.).

Podrían apreciarse ciertas diferencias en la estrategias de explotación y aprovechamiento de materia prima. En el tránsito del Paleolítico Inferior al Paleolítico Medio, los yacimientos apuntan a la existencia de una mayor escasez de núcleos (BN1GE) junto a un repertorio sobre lasca (BP) poco estandarizado (en ocasiones dándose las fases de captación-transformación y consumo en un mismo espacio). Por el contrario en momentos posteriores, nos encontramos con una mayor presencia de núcleos (BN1GE) y lascas estandarizadas (BP1G y $\mathrm{BP} 2 \mathrm{G}$ ); la fase consumo se encontraría presumiblemente en otros contextos, que por el momento no han sido identificados. Igualmente esta diferencia porcentual de categorías podría venir explicada por otras razones.

Como comentábamos al inicio de este apartado, también en la Meseta sur contamos con ejemplos de yacimientos de carácter superficial que pueden constatar los mismos modelos de captación, para periodos similares. Muy conocido el yacimiento de Porzuna (Vallespí 1985) y el Guadiana en Ciudad Real. En este ejemplo, la materia prima (cantos rodados) procede del desmantelamiento de la terraza baja del mismo río, sobre el que se habría desarrollado igualmente una intensa actividad de talla. Más recientemente han sido estudiados yacimientos con características similares, uno en el Cerro del Molino (Camuñas, Toledo; López Recio et al. e.p.), donde el aprovisionamiento se produce sobre conglomerados residuales que han quedado en resalte, y la Casa de la Mina II, en Ciudad Real (Martín Blanco et al. 1994), desarrollado sobre un abanico aluvial.

\section{El Paleolítico Superior}

En el Paleolítico Superior, cambia la distribución de los yacimientos madrileños, disminuyendo aparentemente en número y en dispersión. Se confirma en todo caso la ocupación en la zona serrana (cabeceras del Jarama, Henares y Sorbe en Guadalajara), en yacimientos como los de Cueva del Turismo, Abrigo de los Enebrales, Cueva del Reno, o Abrigo de Peña Capón (Alcolea et al. 1997) y la presencia de una importante concentración de yacimientos, quizás solutrenses, en el curso medio del Manzanares (Merlo 1984), relacionados probablemente con el aprovechamiento recursos líticos de calidad. Es el caso de El Sotillo, Valdivia, Nicasio Poyato y Delicias, El Cojo, (Almagro Basch 1970; Jordá 1989) entre otros, donde abunda el material foliáceo (Pérez de Barradas 1935). En referencia a Las Delicias, Obermaier y Wernert (1918) ya comentaban la posibilidad de que se tratase de un taller por la abundancia de restos de talla en asociación a núcleos y bases naturales. Esta industria presentada como presolutrense por Jordá (1989) en Las Delicias, puede estar representando la fase de un trabajo inicial relacionado con la explotación y preparación de piezas foliáceas. No obstante habría que admitir la posibilidad de que nos encontrásemos ante industrias atípicas en el contexto general de la Península, adscritas a momentos avanzados del Paleolítico Medio (com. pers. M. Santonja; ver Santonja et al., en este mismo volumen).

Sobre la mayoría de estos yacimientos pesa el problema de la ausencia de dataciones absolutas, dado que por las condiciones de su génesis se presentan en la mayoría de los casos como el resultado de la mezcla y alteración de conjuntos (Enamorado 1989; Sánchez Sastre 1985). En la actualidad y gracias al Proyecto de Investigación de la Comunidad de Madrid (Ref. $n^{\circ}$ 06-0180-2000) hemos iniciado la revisión de parte de los fondos de la Colección Bento que puede ofrecer nuevos datos de interés en la interpretación de los modelos de explotación de los recursos líticos del área madrileña. 
En el siguiente cuadro hemos esbozado algunos de los rasgos que deberían contrastarse a partir de una muestra mayor de yacimientos en nuestro entorno y que resume las principales ideas señaladas a lo largo del trabajo.

\begin{tabular}{|l|l|l|l|}
\cline { 2 - 4 } \multicolumn{1}{c|}{} & PAL. INFERIOR & \multicolumn{1}{c|}{ PAL. MEDIO } & PAL. SUPERIOR \\
\hline Localización & Fluvial & Fluvial /interior & Fluvial \\
\hline Densidad y extensión de los restos & Media & Alta & Media alta \\
\hline Carácter del depósito de materia prima & Agregado & Agregado/disperso & $*$ \\
\hline Grado de transformación a partir de restos & Bajo & Medio/alto & Alto \\
\hline Fases de trabajo & Iniciales & Iniciales/Finales? & Todas las fases \\
\hline Calidad de materia prima & Baja & Media & Media alta \\
\hline Presencia materiales foráneos & Media/baja & Baja & Media/baja \\
\hline Tratamientos & Nulo & Nulo & Constatado \\
\hline Morfología de las bases naturales & Ortogonales & Ortogonales /globulares & $*$ \\
\hline
\end{tabular}

* carecemos de datos hasta el momento

\section{POSIBILIDADES DE ANÁLISIS DE COLECCIONES ANTIGUAS Y DE SUPERFICIE: EL PALEOLÍTICO SUPERIOR EN EL ÁMBITO MADRILEÑO}

Casi todos los datos que hasta el momento se poseen sobre el Paleolítico Superior madrileño han sido obtenidos a partir de la revisión de colecciones antiguas; su análisis resulta por tanto esencial para el conocimiento de las características de la ocupación en fechas recientes.

En cuanto a las posibilidades de estudio que presentan, cabría establecer una diferenciación entre conjuntos de superficie y las colecciones antiguas. Los conjuntos procedentes de prospecciones o de recogidas superficiales se caracterizan por presentar una difícil atribución cronológica, dadas las circunstancias que normalmente conducen a la aparición de los materiales. Este es un problema que puede ser redefinido en la medida en que sondeos o excavaciones posteriores pueden confirmar o negar la existencia de secuencias estratigráficas fértiles asociadas a estos conjuntos hallados en superficie. En cualquier caso las posibilidades de análisis desde un punto de vista espacial, incluso en el caso de que habláramos en origen de un suelo de ocupación, son muy escasas por no decir nulas.

En todo momento resulta esencial tratar de discriminar los agentes (siempre variados) que han contribuido a que se produzca el hallazgo de restos en superficie. Así, un yacimiento en posición fuertemente alterada, como puede ser el caso de un nivel de terraza de alta energía, presenta grandes dificultades de estudio para profundizar en el conocimiento de la compartimentación de las actividades. Igualmente es más que probable que un repertorio de estas características, dada la propia dinámica erosiva de los ríos (Santonja 1992), haya mezclado lotes de distintos yacimientos y momentos.

Pero también es cierto (Freeman 1992) que para obtener una visión de conjunto (técnica al menos) de un periodo amplio, los yacimientos bien conservados pueden llevar a la confusión, en especial si están excavados de forma parcial. Ello sería resultado lógico de la compartimentación funcional del espacio en una cueva. Ello podría haber conducido a que las recogidas de superficie hayan sido por lo general maltratadas desde un punto de vista científico al limitar en exceso su capacidad informativa. Es un problema de saber hasta donde podemos llegar. 
En cuanto a las colecciones antiguas, la opinión generalizada es que la capacidad de información que éstas ofrecen es todavía si cabe más limitada. Alguna de las razones que tradicionalmente suelen argumentarse en contra de las posibilidades de estos conjuntos, esta la de la selección de los ejemplares recogidos (tendencia a seleccionar piezas especiales o de museo). Estos "fósiles directores" han sido directa o indirectamente los culpables de una estructuración de la Prehistoria que aún hoy asumimos. En cualquier caso es cierto que una selección del conjunto recolectado aumenta más las dificultades de su estudio especialmente si lo que se persigue es una interpretación tecnofuncional del sitio en origen. Pero el que nos falten piezas de un puzzle no significa que no podamos reconocer a grandes rasgos la imagen representada.

La falta de rigor en la recogida de los testimonios, implica que por lo general se desconocen las condiciones en que se produce la recogida, ¿es un contexto estratigráfico?, ¿son recogidas aleatorias?, ¿están realizadas en primera persona o bien son recompras?, etc. La actitud a adoptar en estos casos puede ser muy personal. Si no existen referencias sobre las condiciones de recogida nada podemos hacer en este sentido y nuestro examen deberá limitarse a reinterpretar desde el conocimiento que poseemos en la actualidad, los testimonios dejando clara su limitación. De existir datos sobre las circunstancias de la recogida (caso en que se encuentra el material de la colección Bento) podemos optar por creer o no lo que nos transmiten nuestros colegas, y en función de ello dar un mayor o menor valor arqueológico a los datos.

\section{APROXIMACIÓN A LOS PROCESOS TÉCNICOS EN EL CONJUNTO DE LA COLECCIÓN BENTO}

Como comentábamos, en la actualidad hemos iniciado el estudio de la Colección Bento, depositada desde 1936 en el Museo Arqueológico de Cataluña (Barcelona). Esta Colección estudiada por D. José Pérez de Barradas (1935) se compone de una extensa muestra de materiales líticos y cerámicos (estudiados en otro capítulo de esta obra), que esta ofreciendo datos de interés en la comprensión del Paleolítico Superior madrileño.

En ella están recogidos materiales de los yacimientos de Valdivia, Arenero de Martínez, El Cojo, Nicasio Poyato, Prado de los Ganaderos y Santiago, entre otros. Al menos en los conjuntos anteriores, sí parece existir una relativa contextualización geológica que adscribe los materiales a los niveles estratigráficos determinados. En los materiales que hemos observado se aprecian claramente secuencias técnicas que incluyen procesos de talla bifacial por su aspecto morfotécnico asimilable inicialmente al Solutrense (ver Figs. 1 y 2.; Lám. I) así como secuencias laminares con una abundante representación en ambos casos.

La presencia de materiales rodados podría indicar la intrusión de piezas por el desmantelamiento de terrazas aguas arriba, y una posible falta de rigor en la contextualización geológica de los materiales. En cualquier caso la muestra analizada presenta los siguientes aspectos:

1. Se trata de una muestra en la que se han sesgado productos según dos criterios. Primero por sus rasgos técnico-tipológicos, lo que determina una decantación a la recogida de piezas foliáceas y laminares obviando materiales corticales y de acondicionamiento. Segundo, por su tamaño, que aunque en algunas ocasiones nos sorprende con la recogida de puntas de dorso rebajado de muy pequeño tamaño (Fig.2.; Lám.I) en la inmensa mayoría de los casos se decanta hacia recogida de piezas voluminosas. La aparición de útiles de pequeñas dimensiones en la colección, nos lleva a pensar que las vías de adquisición de estos materiales, debieron incluir la recogida de piezas sobre el tamiz empleado por los obreros (Lám. II). Por otra parte, las instrucciones que D. J. Bento recibe del propio Pérez de Barradas son muy precisas respecto a la calidad de la recogida:

“... El Sr. Bento anotó en todo momento la procedencia de los objetos, no sólo por lo que se refiere a la localidad o yacimiento, sino también a las capas del terreno de que procedían (...) Le hicimos 
comprender que los objetos, por muy valiosos que fueran, no tienen valor si se desconoce o se duda de la procedencia" (Barradas 1935: 3).

2. Los materiales presentan un estado de conservación variado, que va desde las piezas muy patinadas y con aristas suavizadas hasta material muy fresco. El examen de la colección nos ha permitido localizar pátinas que recuerdan el tratamiento térmico (material bifacial fundamentalmente) que creemos han debido influir, además de en los criterios empleados por Pérez de Barradas en su publicación de 1935, en el aspecto final de los materiales. No obstante su existencia se corresponde lógicamente con la exigencia que la fabricación de estas piezas requiere.

Aunque para ello nos basamos tan sólo en apreciaciones experimentales (Callahan 1979), pensamos que los materiales bifaciales, responden en gran parte a la existencia de numerosos accidentes y ensayos que explican su abandono; en general abundan piezas inacabadas o con fracturas diametrales, paros y reflejados, sobrepasados o accidentes derivados del estado de la materia prima o incluso de la pericia técnica de los talladores. Este hecho no es ajeno a otros yacimientos peninsulares, incluso en supuestos espacios de hábitat (Maíllo Fernández 1999).

3. Existe un desigual reparto de los accidentes entre los conjuntos, de manera que son mucho más numerosos en los materiales bifaciales respecto de los laminares. Esta desigualdad es resultado tanto del riesgo que entraña la reducción bifacial hasta los espesores "solutrenses", como de la frecuente presencia de geodas y fisuras en la materia prima.

4. Resulta también llamativo (Fig. 3) la concentración de todos estos yacimientos a nivel espacial, localizándose en un área muy concreta del tramo sur del Valle del Manzanares. Esta concentración se explicaría por la existencia de una actividad industrial (areneros) muy desarrollada en esta zona, tanto quizás por una concentración de las actividades prehistóricas en puntos de captación conocidos $\mathrm{y}$ visitados recurrentemente.

Igualmente la presencia de conjuntos de estas fechas parece haberse comprobado para contextos ecológicos complementarios como es el caso del Sistema Central en la zona de Guadalajara (Alcolea et al. 1997).

La Cuenca Baja del Manzanares podría tratarse quizás de una zona de captación, aunque nos surgen ciertas dudas, si atendemos al hecho de que en las excavaciones antiguas no suele citarse la existencia de una clara asociación entre materia prima sin trabajar y materia prima trabajada. Este punto sin embargo, sí aparece comentado en el caso de yacimientos como Las Carolinas o Las Delicias en los que existe algunos ejemplares poco característicos de lo que los autores que lo estudiaron definen como puntas "tenuifoliadas", y que posteriormente para el caso de El Sotillo, han sido reinterpretadas como materiales posiblemente solutrenses (Martínez de Merlo 1984).

El hecho de que aparezcan piezas muy elaboradas, no debe tampoco interpretarse como un argumento para descartar el carácter de zona de aprovisionamiento y transformación, ya que la presencia de materiales muy elaborados en zonas cercanas a afloramientos de materia prima es un hecho que tiene lugar desde fases finales del Paleolítico Medio (Svodoba 1983), por razones de economía de esfuerzos (tecnología comprometida que implica numerosos accidentes, resulta más ventajoso el realizarla cerca del afloramiento donde la materia prima abunda).

\section{CONSIDERACIONES FINALES}

Suele asumirse (Tixier et al. 1980) que la materia prima condiciona el resultado técnico a obtener. Sin embargo el argumento podría platearse igualmente en sentido inverso: la exigencia, y por tanto el grado de selección de las materias primas, es un fenómeno que varía con el tiempo, en relación con la propia evolución técnica de las comunidades prehistóricas. 
Reivindicamos el que este proceso, que es apreciable con claridad en fase recientes (Neolítico y empleo de obsidianas; o el propio tratamiento térmico como respuesta a exigencias específicas), sea válido con algunos matices para fases finales del Paleolítico. Sin embargo, el concepto de calidad de la materia prima no debe basarse solamente en la clasificación petrológica de las distintas variedades, como sucede en el caso de las puntas solutrenses en cuarcita de calidad excelente (Straus 1983).

Queremos insistir, a efectos de los procesos de captación someramente analizados en este trabajo, en la necesidad de evaluar en cada caso la influencia del estado de la materia prima en los depósitos, y de las circunstancias y limitaciones que la presentación de misma puede imponer en la fabricación de los productos de alta exigencia en la fabricación. Por otra parte, cabe insistir en la necesidad de reclasificar la naturaleza de los depósitos primarios/secundarios, introduciendo matices tales como la presentación y grado de agregación que en ellos ofrece la materia prima.

Para los yacimientos que pueden enmarcarse dentro de una funcionalidad relacionada con la captación lítica, no es aceptable emprender el estudio de estos conjuntos desde una clasificación tipológica de los restos, ya que lógicamente las fases técnicas que se manifiestan en talleres pueden variar. Si tenemos en cuenta el largo y delicado proceso que conduce a la elaboración de material bifacial comprenderemos la aparición de piezas correspondientes a distintas fases de abandono, que como es natural no se ajustan necesariamente a las tipologías elaboradas para productos finalizados (Hayden y Hutchings 1989; Díez Martín 2000). Igualmente, en estas áreas cabría detectar procesos asociados a fases de aprendizaje (nadie ha nacido sabiendo tallar en ningún momento de la Prehistoria) asociados a lugares con abundante materia prima, lo que podría producir evidencias con una gran heterogeneidad, que llevarían desde una concepción simplista del análisis tipológico, a su inclusión en estadios culturales diferentes aparentemente más arcaicos.

Los nuevos datos de los que disponemos en la actualidad, a pesar de las limitaciones que la muestra ofrece, señalan la existencia de un alto grado de continuidad en la ocupación y explotación de nuestra región durante el Paleolítico, aunque pueden anotarse algunos cambios en su naturaleza y distribución. La distribución por categorías parece diferente en los conjuntos del Paleolítico Superior, si bien la limitaciones de la muestra con la que trabajamos (Colección Bento) acota las posibilidades interpretativas. Constatamos la ausencia de bases naturales o bloques de tanteo exploratorio en el área que nos ocupa, por lo que la fase de captación no parece probada. Sin embargo, tal como es conocido en otras áreas (Dordogna, Cantábrico) la recurrencia geográfica en los lugares de captación parece haberse mantenido durante largos periodos de tiempo. 


\section{BIBLIOGRAFÍA CITADA}

ALCOLEA, J.; BALBÍN, R.; GARCÍA, M.A.; JIMÉNEZ, P.J. (1997): "Nuevos descubrimientos de arte rupestre paleolítico en el centro de la Península Ibérica: La cueva del Reno (Valdesotos, Guadalajara)", II Congreso de Arqueología Peninsular: 239-257. Zamora.

ALMAGRO BASCH, M. (1970): Manual de Historia Universal. Tomo I. Prehistoria. Espasa Calpe.

BAENA PREYSLER, J. (1994 a): "El Paleolítico Inferior y Medio en el Valle del Río Manzanares: nuevos criterios para su investigación y prospección", EPAM 9: 149-152.

BAENA PREYSLER, J. (1994 b): El paleolítico Inferior y Medio en la región sur de Madrid: Estudio de las facies de talleres. Edición en microfichas de Tesis Doctoral Universidad Autónoma de Madrid.

BAENA PREYSLER, J.; CONDE, C. y CARRIÓN, E. (1997): "Estrategias de captación durante el Paleolítico Antiguo en la región sur de Madrid", Rubricatum 2: 69-76.

BAENA PREYSLER, J. e IBÁÑEZ, F. (1996): “El yacimiento paleolítico de Las Fronteras”, Reunión de Arqueología Madrileña: 181-186.

BAENA PREYSLER, J. et al. (2000): "Paleolítico y Epipaleolítico" en V.V.A.A.: La Arqueología Madrileña en el Final del Siglo XX: Desde la Prehistoria hasta el Año 2000. Boletín de la Real Sociedad Española de Amigos de la Arqueología. XXX Aniversario 1969-1999.

BERNALDO DE QUIRÓS, F. y CABRERA, V. (1979): "Problemas generales del Paleolítico Medio y Superior en la provincia de Madrid", I Jornadas de Estudios sobre la Prov. de Madrid. Diputación Provincial de Madrid.

CABRA, P.; GOY, J.L.; HOYOS, M. y ZAZO, C. (1983): "Estudio geomorfológico del Cuaternario y de las formaciones superficiales del sector meridional de la sierra de la cabrera", Tecniterrae, año IX, 51:32-42.

BOSINSKI, G. (1995): "Stone artefacts of European Lower Paleolithic. A sort note", Analecta Praestorica Leidensia 27. Leiden.

CARBONELL et al. (1995): “Atapuerca (Trinchera-Galería, Spain: Strategies and operational models in lithic industries", Cahier Noir 7: 41-83.

CARRIÓN SANTAFÉ, E. y BAENA PREYSLER, J. (1999): "El Habario, un yacimiento musteriense al aire libre en los Picos de Europa cántabros", Espacio, Tiempo y Forma, Serie I, Prehistoria y Arqueología 12: 81-101.

CALLAHAN, E. (1979): "The Basics of biface knapping in the eastern fluted point tradition: a manual for flintknappers and lithic analysis", Archaeology of Eastern North America 7, 1.

COBO, A. y GAMAZO, M. (1983): "Desarrollo de las teorías sobre la edad y formación de las terrazas del Manzanares. Nuevas aportaciones", Homenaje a M. Almagro. Tomo I. Madrid.

COBO, A.; GAMAZO, M.; HOYOS, M. y SOTO, E. (1980): "Avance de los trabajos realizados en el presente año en la zona sur del Manzanares: Areneros del Camino de la Aldehuela y excavaciones en el yacimiento paleolítico de Perales del Río", II Jornadas de Estudios sobre la Provincia de Madrid 2: 38-43. Diputación Provincial de Madrid.

COBO, A.; GAMAZO, M.; HOYOS, M. y SOTO, E. (1979): "Los yacimientos Paleolíticos de las terrazas del Manzanares. Estado actual de la cuestión", I Jornadas de estudios sobre la Provincia de Madrid: 38-43. Dip. Prov. de Madrid.

CONARD, N.J. (1998): "Middle Paleolithic Settlement in the Rhineland", en V.V.A.A.: XIII International Congress of Prehistoric and Protohistoric Sciences: 255-268. Forly. Proceedings.

DIBBLE, H. (1988): “The Interpretation of Middle Paleolithic Scraper Reduction Patterns", en OTTE, M. (Ed.): L'Homme de Neeandertal. LA TECHNIQUE. Vol. 4: 49-58. Lieja. 
ENAMORADO, J. (1984a): "Las facies del Musteriense en el Valle del Manzanares según Pérez de Barradas: bases para una revisión”, Estudios de Prehistoria y Arqueología Madrileña. Madrid.

ENAMORADO, J. (1984b): "El Esbaikiense: sus implicaciones en la definición de una facies del Musteriense en el Valle del Manzanares", Inst. Esp. de Prehistoria: 293-303. Madrid.

ENAMORADO, J. (1989): "La Torrecilla y La Parra: análisis de la industria lítica de dos yacimientos de época paleolítica en el Valle del Manzanares, Madrid”, Boletín del Museo Arqueológico Nacional VII: 9-27.

DÍEZ MARTÍN, F. (2000): El poblamiento paleolítico en los páramos del Duero. Ed. Universidad de Valladolid.

DOMÍNGUEZ RODRIGO, M.(1994): El origen del comportamiento humano. Ed Tipo. Madrid.

FERNÁNDEZ PERIS, J. (1998): "La Coca (Aspe, Alicante). Área de aprovisionamiento y talla del Paleolítico Medio”, Recerques del Museu D' Alcoi 7: 9-46. Alicante.

FLÉBOT AUGUSTINS, J. (1999): "Raw Material Transport Patterns and Settlement System in the European Lower and Middle Palaeolithic: Continuity, Change and Variability”, en ROEBROKERS, W. y GAMBLE, C.: The Middle Paleolithic Ocupation of Europe: 193-214.

FLOSS, H. (1991): "Raw materials procurement in the palaeolothic of Western Germany", Abstracts del VI Flint International Symposium: 224-226. Madrid.

FREEMAN, L.G. (1992): "Mousterian Facies in Spain: New data from Morín Level 16", en DIBBLE, H.L. y MELLARS, P.(Ed.): Thre Middle Paleolithic: Adaptation, Behaviour and Variability: 113-125. Pensylvania.

GAMAZO, M.; COBO, A. y MARTÍNEZ DE MERLO, A. (1983): "El yacimiento Achelense de Perales del Río (campañas de excavación de 1980 y 1981)”, Homenaje al Prof. Martín Almagro Basch: 95-103. Ministerio de Cultura. Madrid.

GAMAZO, M. (1982): "Prospecciones en las terrazas de la margen derecha del río Manzanares (Getafe, Rivas-Vaciamadrid)", Noticiario Arqueológico Hispánico 14. Madrid.

GENESTE, J.M. (1988): "Systemes d'approvisionnement en materies premieres au Paléolithique Moyen et Paléolithique Supérior en Aquitanie”, en OTTE, M.(Ed.): L'Homme de Neeandertal. LA MUTATION8: 61-70. Lieja.

HAYDEN, B. y HUTCHINGS, K. (1989): “Whither the billet flake?”, Experiments in Lithic Technology, BAR International Series: 235-255.

ISAAC, G. (1971): "The diet of early man: aspect of archaeological evidence from Lower and Middle Pleistocene sites in Africa", World Archaeology Vol. II, 3.

JORDÁ, F. (1989): "Paleolítico", en V.V.A.A.: Historia de España. Tomo I (Prehistoria): 8-150.

JORDÁ, J.F. y GARCÍA, M.A. (1989): "Las representaciones de glotón (Gulo gulo, L) en el arte paleolítico pirenaico y un nuevo hallazgo de arte mueble en el alto valle del Jarama (Guadalajara)", Espacio, Tiempo y Forma, UNED.

KLARIC, L. (1998): "Estude de l'Industrie lithique du site de Garet (Landes)", en V.V.A.A.: Comportement techniques et écnomiques des societés au Paléolothique Supérieur dans le contexte pyrénéen. Apports de la Technologie lithique: 32-41. Proyecto colectivo de Investigación. PCR investigador responsable Natalie Cazals.

KUHN, S.L. (1995): Mousterian Lithic Technology. An Ecological Perspective. Princeton.

LOODTS, I. (1998): "Una approche comportmenal de L'Homme de Neandertal. La industrie lithique de la couche 1 de l'Grotte Scladina. Économies des Matieres Premieres et Coexistence de Chaines Operatoires au Paléolithique Moyen Récent", en V.V.A.A.: Recherches aux Grottes de Sclayn II: 69-101. Lieja.

LÓPEZ COVACHO, L.; ORTIZ DEL CUETO, J.R. y RODRÍGUEZ Y FUENTE, M. (1996): "El yacimiento preshistórico de Pedazo del Muerto (Pinto, Madrid)", Reunión de Arqueología Madrileña: 213-214. 
MAÍLLO FERNÁNDEZ, M. (1999): "Esquemas operativos y conocimiento técnico; el caso del yacimiento solutrense del Vale Almoíha (Tores Vedras, Portugal)", Espacio Tiempo y Forma, Seire I, 12: 185-214.

MÁRQUEZ TRIGUERO, E. (1965): "Sobre un nuevo yacimiento del Paleolítico en Coslada (Madrid)", Not. y comun. del Inst.Geológ. y Minero de España 78. Madrid.

MAROTO, J. et al., (1996): "Cultural Change Between Middle and Upper Plaeolithic in Catalonia", en CARBONELL, E. y VAQUERO, M.: The Last Neandertal. The First Anatomically Modern Humans. Cultural Change and Human Evolution: 219-250. Tarragona.

MARTOS, J.A.(1998): "Elefantes e intervención humana en los yacimientos del Pleistoceno Inferior y Medio de Africa y Europa", Trabajos de Prehistoria 51: 19-38.

MARTÍN BLANCO, P. et al. (1994): "Identificación de cadenas operativas líticas en el sitio arqueológico de Casa de la Mina II (Argamasilla de Alba, C. Real). Consideraciones acerca de los yacimientos superficiales sin contexto estratigráfico", Zephyrus 47: 15-40. Salamanca.

MARTÍNEZ DE MERLO, A. (1984): "El Paleolítico Superior en el valle del Manzanares: el yacimiento de El Sotillo", Bol. del Museo Arqueológico Nacional II: 47-68. Madrid.

MELÉNDEZ, E. y AGUIRRE, E. (1958): "Hallazgo de Elephas en la terraza media del río Manzanares (Villaverde, Madrid)", Las Ciencias XXIII- 4: 597-605.

MONTES, R. (1998): Los complejos industriales del Paleolítico Inferior en la Región Cantábrica. Tesis Doctoral. Universidad de Cantabria (Inédita).

OBERMAIER H. (1917): "El yacimiento prehistórico de Las Carolinas", Comisión de Investigaciones. Paleontológicas y Prehistóricas. Memoria 16.

OBERMAIER, H. y WERNERT, P. (1918): "Yacimiento paleolítico de las Delicias", Memoria de la Real Soc. Esp. de Hist. Natural, XI. Memoria 1. Madrid.

OBERMAIER, H.; WERNERT, P. y PÉREZ DE BARRADAS, J. (1921): "El Cuaternario de las canteras de Vallecas (Madrid)", Bol. Inst. Geol. de España, XLII. Madrid.

ORTEGA, I. (1998): "Presentation des productions laminaires et lamellaires aurignaciennes du niveau aurignacien de Barbas (Dordogne)", en V.V.A.A. Comportement techniques et écnomiques des societés au paléolothique supérieur dans le contexte pyrénéen. Apports de la Technologie lithique: 42-54. Proyecto colectivo de Investigación. PCR investigador responsable Natalie Cazals.

PANERA, J.; RUBIO, S. y MARTOS, J. (e.p.): "Nuevas intervenciones arqueológicas en los valles del Manzanares y Jarama (Madrid): puesta en valor de sus depósitos pleistocenos", Preactas del 3er Congreso de Arqueología Peninsular: 21-27 septiembre.

PANERA GALLEGO, J.; RUBIO JARA S. y MARTOS ROMERO, J.A. (2000): "Intervenciones arqueológicas en los valles del Manzanares y Jarama (Madrid): puesta en valor de sus depósitos pleistocenos", Actas del III Congreso de Arqueología de la Península Ibérica: 59-69. Vila Real, Portugal.

PASTOR MUÑOZ, F.J. (e.p.): "Ocupaciones prehistóricas en el curso final del río Sorbe (Guadalajara)", Revista Wad-Al-Hayara. Diputación Provincial.

PASTOR, F.J. (1976): "Un yacimiento epipaleolítico en las riberas del río Sorbe", Boletín informativo de la Asociación de Amigos de la Arqueología 5: 5-7

PÉREZ GONZÁLEZ, A.(1971): "Estudio de los procesos de hundimiento en el valle del río Jarama y sus terrazas (nota preliminar)", Estudios Geológicos XXVII-4: 317-324.

PÉREZ DE BARRADAS, J.; OBERMAIER, H. y WERNERT, P. (1921): "El Cuaternario de las Canteras de Vallecas de Madrid", Bol. Inst. Geol. de España XLII. Madrid.

PRIEGO M.C.; QUERO, S.; GAMAZO, M. y GÁLVEZ, P. (1979-1980): "Prehistoria y Edad Antigua en el área de Madrid", en V.V.A.A.: Madrid. Testimonios de su historia hasta 1875. Ayuntamiento de Madrid. Madrid. 
QUERO, S. (1994): "Excavación del elefante de Orcasitas", Estudios de Prehistoria y Arqueología Madrileñas 9: 11-16.

QUERO, S. y PRIEGO, M.C. (1979): "Prospecciones y excavaciones recientes del Instituto Arqueológico Municipal”, I Jornadas de Estudios sobre la Provincia de Madrid. Dip. Prov. Madrid.

QUEROL, M. A. et al. (1980): "El Paleolítico en la provincia de Madrid", II Jornadas de Estudios sobre la Provincia de Madrid. Madrid.

RODRÍGUEZ CIFUENTES, M.; ARIAS CABEZUDO, P. y HERNÁNDEZ, M. (1996): "El yacimiento paleolítico de La Dehesa (Coslada, Madrid)", Reunión de Arqueología Madrileña: 251-253.

ROLLAND, N. (1998): "Middle Paleolithic Settlement System and Mousterian Complex Assemblage Type Variability”, en V.V.A.A.XIII International Congress of Prehistoric and Protohistoric Sciences. 293-298. Forly. Proceedings.

RUBIO, S.; PANERA, J. y MARTOS, J. (1999): “Autopistas, ferrocarriles y bifaces: ¿Nuevas perspectivas para la investigación del paleolítico en los ríos Manzanares y Jarama?”, Espacio Tiempo y Forma, 12: 67-79.

RUS, I. (1987): “El Paleolítico”, en V.V.A.A. 130 Años de Arqueología Madrileña: 20-43. Real Academia de Bellas Artes de San Fernando, Madrid.

RUS, I. y VELASCO, F. (1993): "El poblamiento Prehistórico de Madrid" en Historia de Madrid, Ed. Complutense, 67-86.

RUS, I. y ENAMORADO, J. (1991): "Flint supply in the Manzanares valley: the acheulian site of Arriaga (Madrid, Spain)", Abstracts del VI Flint International Symposium: 270-273. Madrid.

SÁNCHEZ, J. (1985): "Los yacimientos paleolíticos de El Atajillo, Atajillo del Sastre y López Cañamero en el valle del Manzanares", Est. de Preh. y Arq. madrileña: 75-118. Madrid.

SANTONJA, M. (1977): "Los bifaces del Cerro de San Isidro conservados en el Museo Arqueológico Nacional", Rev. de Archivos bibliotecas y Museos. Madrid.

SANTONJA, M. (1992): "La adaptación al medio en el Paleolítico Inferior de la península ibérica. Elementos para una reflexión", en MOURE, A. (Ed.): Elefantes, ciervos y ovicaprinos: 37-76. Universidad de Cantabria.

RAPOSO, L. y SANTONJA, M. (1995): “The earliest occupation of Europe: The Iberian Peninsula”, Analecta Praehistorica Leindensia 27: 7-25.

SANTONJA, M. (1992): "La adaptación al medio en el Paleolítico Inferior de la Península Ibérica. Elementos para una reflexión", en MOURE, A.: Elefantes, Ciervo y Ovicaprinos. Universidad de Cantabria.

SANTONJA, M. et al. (1997): "Estado actual de la investigación en Ambrona y Torralba (Soria)", en BALBÍN R. y BUENO, P. (Eds.): II Congreso de Arqueología Peninsular, T. I Paleolítico II Neolítico Calcolítico y Bronce: 51-65. Zamora.

SANTONJA, M. ; LÓPEZ, N. y PÉREZ GONZÁLEZ, A.(1980): “Ocupaciones Achelenses en el valle del Jarama (Arganda Madrid)", Dip. Prov. de Madrid.

SILVA, P.; CAÑAVERAS, J.; SÁNCHEZ-MORAL, S.; LARIO, J. y SANZ, E. (1997): “3d soft sediment deformation structures: evidence for quaternary seismicity in the madrid basis, Spain", Terra Nova 9 : 208-212.

STAHL, L. y DETREY, J. (1999): Le site Moustérien d'Alle, Pré Monsieur. Cahiers d'Archeologie Jurasiane 9. Porrentruy.

STRAUS, L.G. (1983): El Solutrense Vasco-Cantábrico. Una nueva perspectiva. Centro de Investigación Museo de Altamira, Monografía $\mathrm{n}^{\circ} 10$.

STRAUS, L.G. (1992): Iberian before the Iberians. The Stone Age History of Cantabrian Spain. University of New Mexico Press. 
SVODOBA, J. (1983): "Raw material sources in Early Upper Paleolithic Moravia. The concept of lithic exploitation areas", Anthropologie XXI/2: 147-158.

TAVOSO, A. (1984): "Réflexion sur l'economie des matiéres prémieres au Moustérian", Bulletin de la Societé Préhistorique Francaise 81/3: 79-82.

TERRADAS, X. (1998): “L'Approvisionnemment en matières premières siliceus sur le versant méridional des pyrénées orientales et sa relation avec la gèneralisation du débitage laminare", en V.V.A.A., Comportements techiques et économiques des societés au Palèolithique supérieur dans contexte pyrénéen. Apport de la Technologie lithique. Proyecto colectivo de Investigación. Responsable: Nathalie Cazals.

TIXIER, J. et al. (1980): Prehistoire de la Pierre taillé. París.

TURQ, A. (1992): "Raw Material and Technological Studies of the Quina Mousterian in Périgord", en DIBBLE, H.L. y MELLARS, P. (Ed.): The Middle Paleolithic. Adaptation, Behaviour and Variability: 75-85. Pensylvania.

VALLESPÍ PÉREZ, E.; CIUDAD SERRANO, A. y GARCÍA SERRANO, R. (1979): Achelense y Musteriense de Porzuna (Ciudad Real). Materiales de superficie, I(Colección E. Oliver). Estudios y Monografías 1. Museo de Ciudad Real.

VALLESPÍ PÉREZ, E.; CIUDAD SERRANO, A. y GARCÍA SERRANO, R. (1985): Achelense y Musteriense de Porzuna (Ciudad Real). Materiales de superficie, II (Muestra de las colecciones de A. Retamosa y M. Expósito). Universidad de Castilla la Mancha. Ciudad Real.

VEGA, G. (1983): “Los problemas del Paleolítico Medio en España”, Homenaje al Prof. Almagro Basch I: $115-129$.

VEGA, G.; RAPOSO, L. y SANTONJA, M. (1999): "Environments and settlement in the Middle Palaeolithic of the Iberian Peninsula", en ROEBROEKS, W. y GAMBLE, C. (Eds.): The Middle Palaeolithic Occupation of Europe: 23-48. University of Leiden.

VERMMERSCH, P.(1988): "Transition from the Middle to Upper Paleolithic in Egyptian Nile Valley", en OTTE, M. (Ed.): L'Homme de Neeandertal. LA MUTATION 8: 241-249. Lieja.

VERMEERSCH, P.; PAULISSEN, E. y VAN PEER, P. (1991): "Palaeolithic chert mining in Egypt", VI Flint International Symposium. Abstracts: 191-194. Madrid. ITGME 

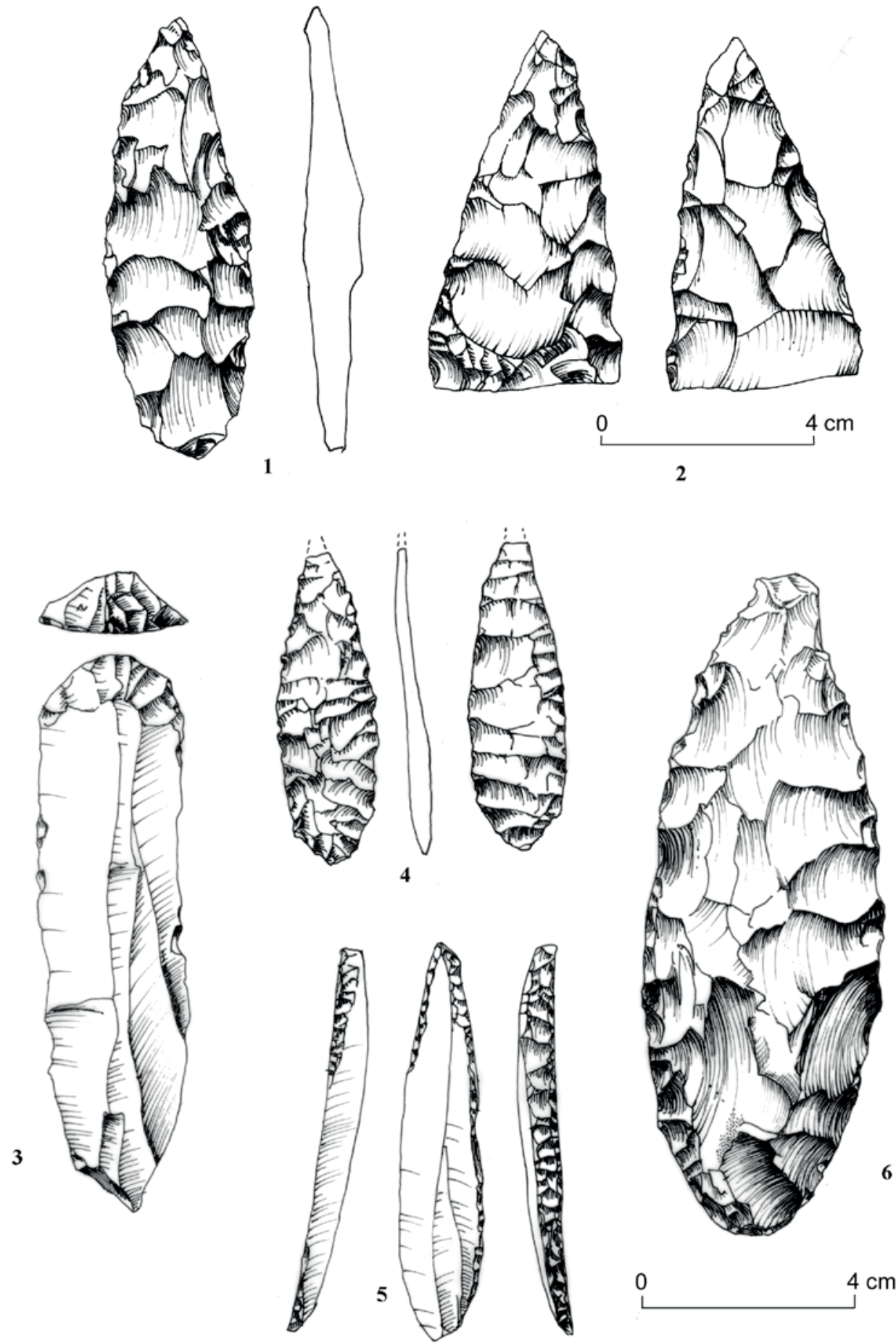

Fig. 1. Paleolítico Superior en el Manzanares. 1 y 2, Valdivia. 3, Nicasio Poyato. 4, 5 y 6, Arenero Martínez. 

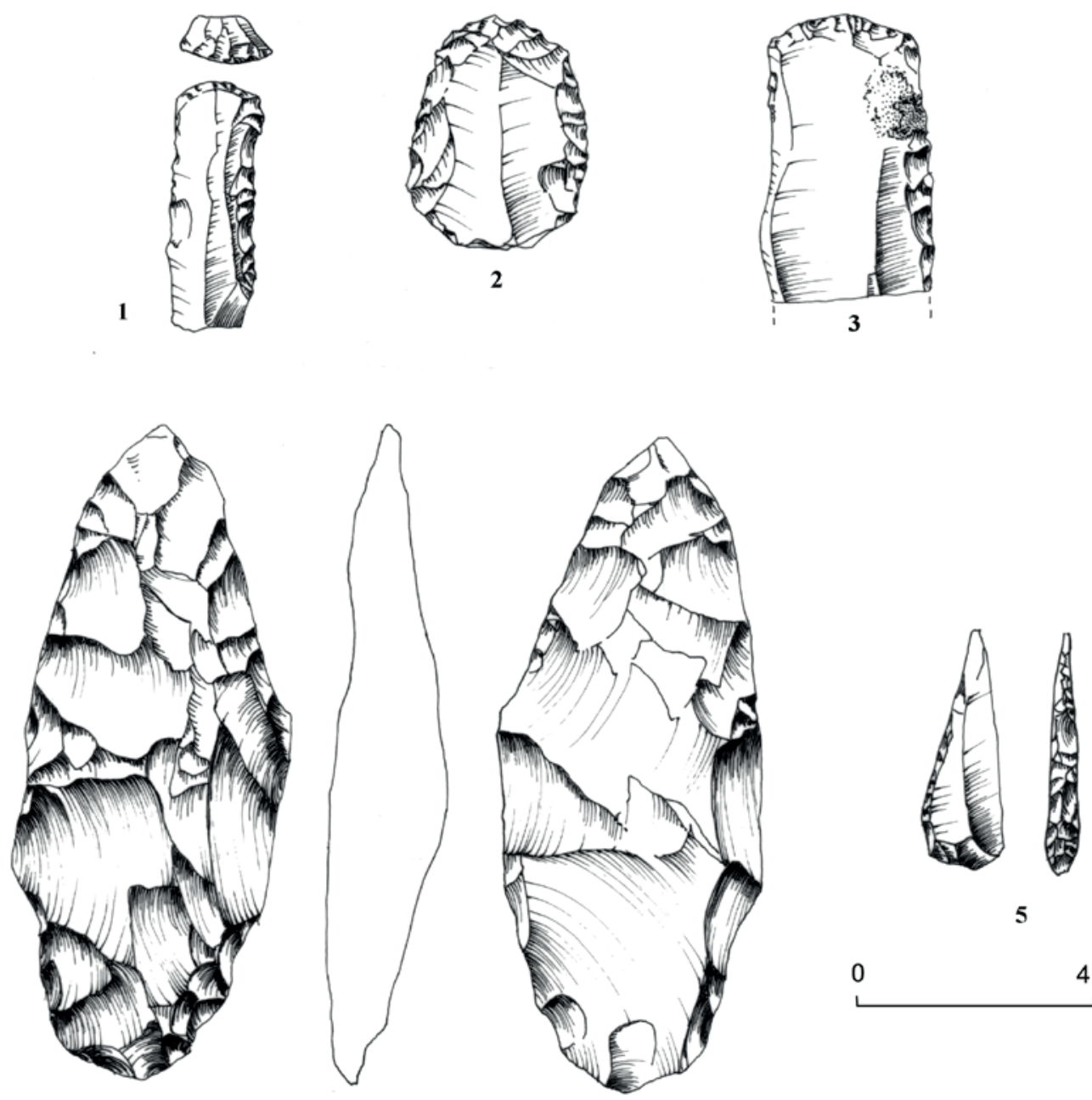

5
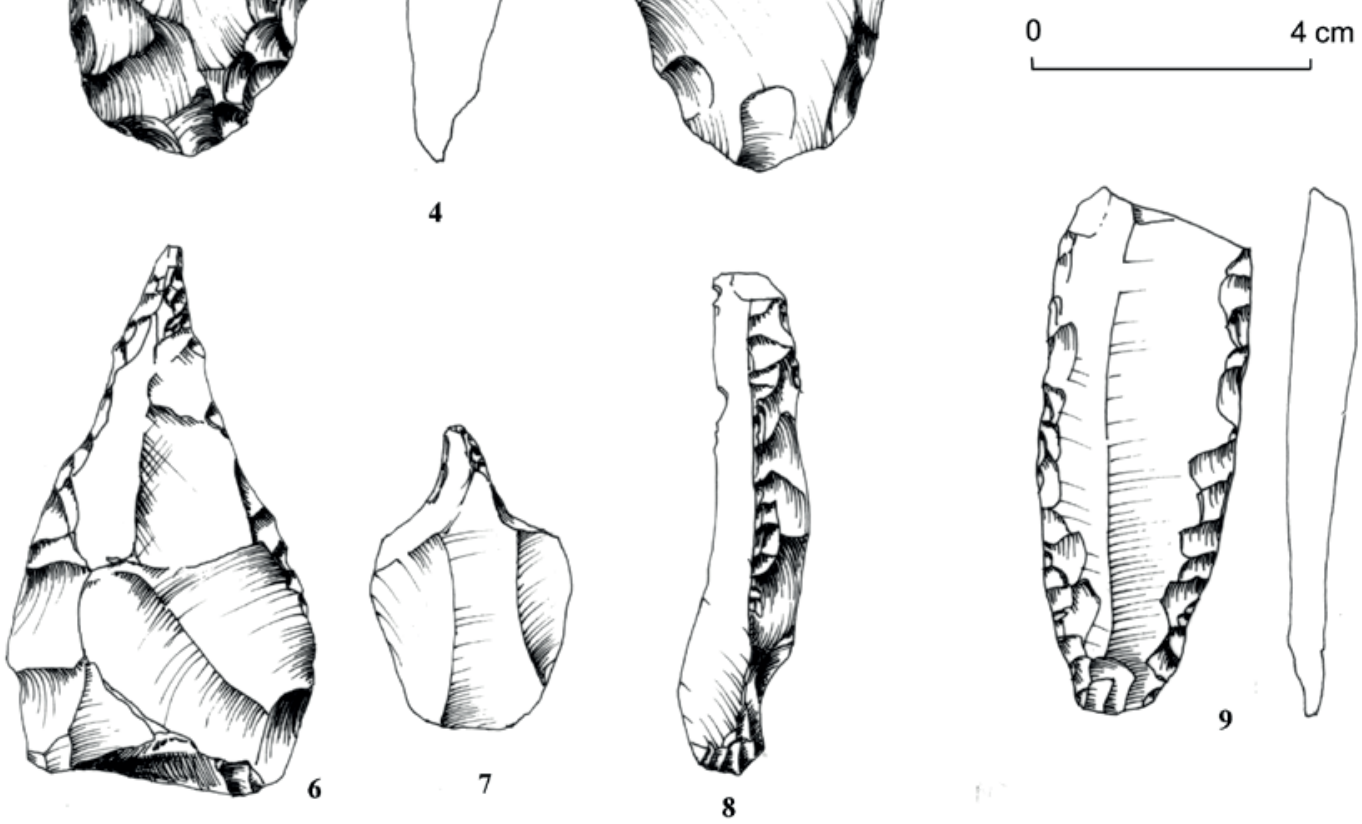

Fig. 2. Paleolítico Superior en el Manzanares. 1, 3, 4, 6, 7, 8, Arenero Martínez. 2, El Cojo. 9, Valdivia.

ISSN: 1133-4525 ISSN-e: 2255-3924

SPAL 9 (2000)

http://dx.doi.org/10.12795/spal.2000.i9.07 


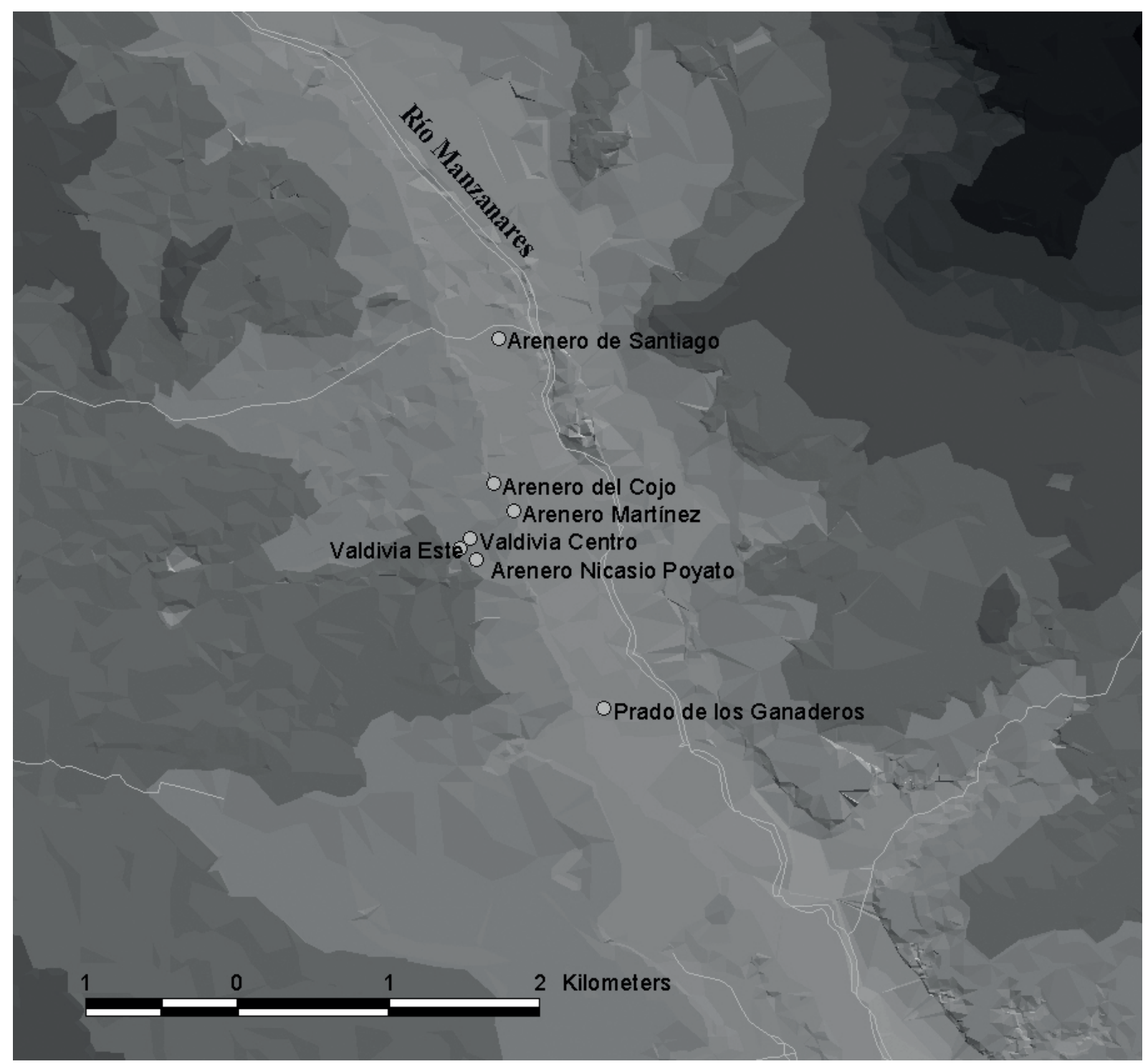

Fig. 3 .Mapa de distribución de yacimientos del Paleolítico Superior contenidos en la Colección Bento; se observa su gran concentración espacial. 

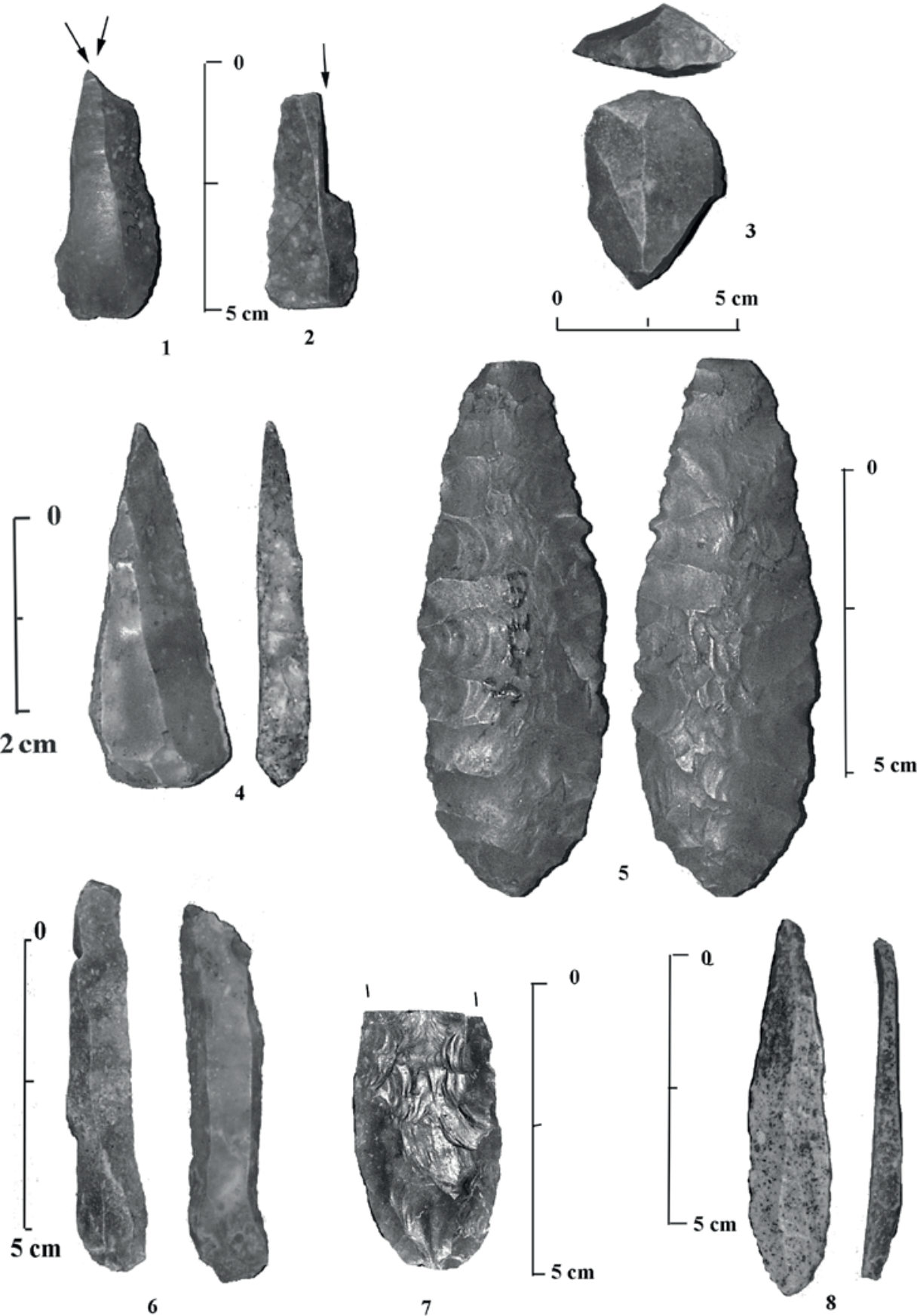

Lámina I. Paleolítico Superior del Manzanares. Piezas de Valdivia y Martínez. 1, 2, 3 y 5, Martínez. 4 y 7 , Valdivia.

ISSN: 1133-4525 ISSN-e: 2255-3924

SPAL 9 (2000)

http://dx.doi.org/10.12795/spal.2000.i9.07 


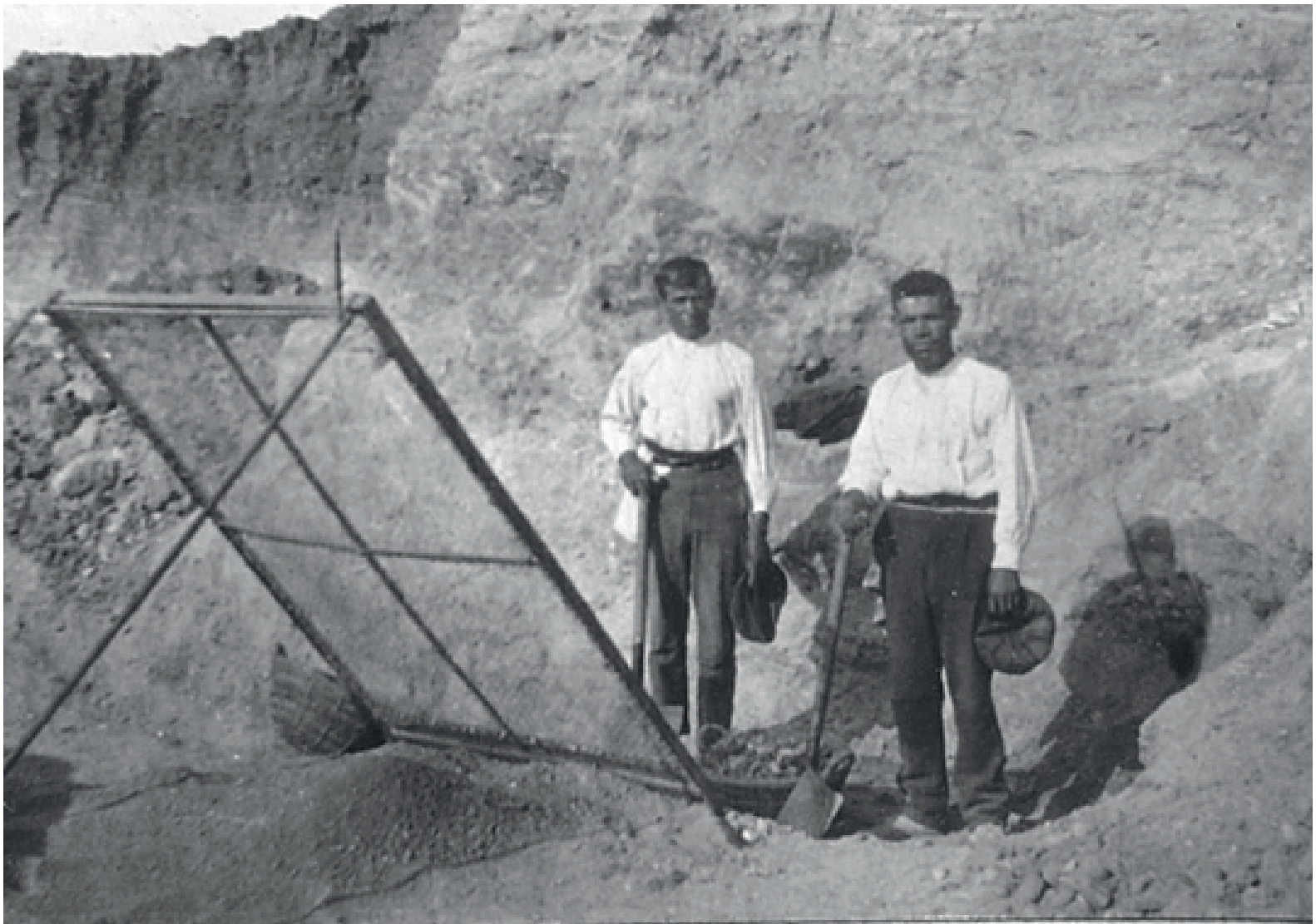

Lámina II. Tamiz utilizado en los trabajos extractivos en el Arenero Parador del Sol, en los años veinte (Agradecemos al Museo de San Isidro (Madrid) la cesión de la imagen para la publicación). 